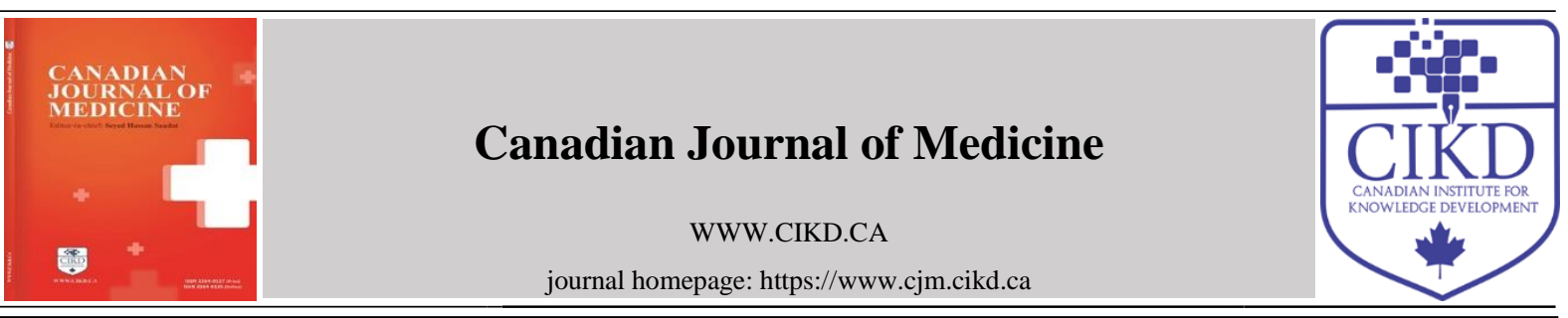

\title{
Evaluating and Mitigating the Challenges of International Students Amidst the COVID- 19 Pandemic: An Overview
}

\author{
Daivat Bhavsar ${ }^{1,2}$, Peter Anto Johnson ${ }^{2,3 *}$, John Christy Johnson ${ }^{2,3}$, Jasrita \\ Singh $^{1,2}$, Austin Albert Mardon ${ }^{2,3}$ \\ ${ }^{1}$ Department of Biochemistry and Biomedical Sciences, McMaster University, Hamilton, \\ Ontario, Canada \\ ${ }^{2}$ Antarctic Institute of Canada, \#103 1191982 St NW, Edmonton AB, T5B 2W4, Canada \\ ${ }^{3}$ Faculty of Medicine \&amp; Dentistry, University of Alberta, Edmonton, Alberta, Canada
}

\begin{abstract}
Keywords:
Canada, COVID-19,

International, Social Justice,

Social Work, Students

Received

02 August 2021

Received in revised form

ABSTRACT

International students are one of the most vulnerable social groups during the COVID-19 pandemic, ignored by social and financial welfare programs. The use of statistics, governmental statements, and academic literature outline the additional hardships faced by post-secondary international students to propose interventions to reduce precarity. The hospitality of educational institutions and response programs towards international students would be crucial for upholding commitments to social justice during these challenging times. This paper can contribute to understanding the role of social work in serving groups most vulnerable to COVID-19.
\end{abstract}

15 September 2021

Accepted

17 September 2021

*Correspondence:

paj1@ualberta.ca

○CIKD Publishing

Regarding the COVID-19 pandemic, universities across North America correctly anticipated a significantly lower percentage of immigrating international students this year due to travel restrictions, the status of study permits, request for acceptance deferrals, and associated gap 
years [1]. According to Statistics Canada, colleges and universities heavily rely on international tuition fees as international students comprise roughly $10-15 \%$ of total enrollments [2]. However, although international students pay fees 2-4 times higher [3] than domestic students' tuition fees, they are most often ignored by media and interventional programs of COVID-19. Universities may sincerely attempt to address mental health issues and student satisfaction during these times, but the unique challenges of their international students are overlooked or generalized. The international students in Canada are hence one of the most vulnerable groups facing precarity amidst the COVID-19 pandemic [4].

This essay discusses the disproportionate challenges that international students are burdened with and evaluates the current measures taken by the Canadian government and educational institutions to improve their quality of life, especially during the COVID-19 pandemic. The paper also investigates the role of social work research to design feasible interventions that would mitigate the social and mental health impact of COVID-19 on international students, regardless of their immigration status (i.e., currently studying in North America or overseas).

\section{Disproportionate COVID-19 Challenges on International Students}

International students face two fundamental challenges: financial crises and the inability to acquire social support. These two aspects can lead to other negative long-range consequences of COVID-19 such as long-term emotional distress, deteriorating mental health, and poor academic performance. Domestic students can also face these challenges; however, international students are generally impacted to a much greater extent due to the precarity they face because of their cultural differences and immigration status. They may not be Canadian but are a largely ignored group in Canadian society.

\section{Financial Crises}

Alongside higher tuition fees, the financial pressures from food, utility, and housing costs, would very much increase the distress that many international students and their families have been experiencing since day 1 of the pandemic. The lack of summer job opportunities, not to mention their initial exclusion from the Canadian Emergency Relief Fund (CERB) [5] and the Summer Jobs Program [6], deprived many students of the financial support they need to access necessities. The international youth is indubitably a significant contributor to the economy, but this does not necessarily reflect their experiences in the labor market. Their foreign status and language fluency or diction either leads to their exploitation as 'cheap labor' or their discrimination from higher-paying, communicative jobs [7]. This discrimination has recently amplified against Chinese students, which comprise the largest ethnic group of international students. A Statistics Canada survey in August found consistent results of Chinese, Korean, and Southeast Asian participants perceiving over a 30\% increase in anti-Asian incidents since the start of the pandemic [8]. These financial hardships of the job-searching process, job discrimination, budgeting, and the constant stress of acquiring necessities would heavily distract the international youth from focusing on their primary objective - educational excellence. 


\section{Acquiring a Social Balance}

Many international students do not have social circles that extend beyond the closed campuses. Although institutions have considered the particular needs of these students to allow residential halls, they are disproportionately isolated from friends and family in their 'ghost-town' campus [9]. In a land foreign to them, the international students often struggle to advocate for themselves and their well-being. Although some international students may have accepted the current situation as it stands and somewhat comfortably adapted to a quarantine lifestyle, many continue to suffer from anxiety with a deteriorating sense of self-esteem and passion for general activities [4]. They can be culturally disadvantaged in developing their social networks or getting help. They would have far fewer people and resources to access as they face emotional distress about their distant families' safety and well-being on top of theirs. Furthermore, those that have safely migrated home (overseas) would also experience similar challenges of interacting with new peers and professors or finding the incentive to participate in on-campus extracurricular activities [10]. The cultural challenges of expanding academic and social networks can not only adversely affect their ability to accomplish academic endeavors but would also limit higher-end opportunities of conducting research, establishing new connections, and achieving interdependent effectiveness. Proactive social responses can and should be implemented to ensure that the post-secondary experience is a well-coordinated learning journey to be completed with the comprehensive support of others.

\section{Social Support Networks and Interventions}

During these prolonged challenging times of the COVID-19 pandemic, international students look hopefully towards their colleges and universities for support and guidance. If educational institutions are unable to provide additional financial aid, then they should invest in social work research to address youth mental health. A Statistics Canada study shows that by far the most reports of deteriorating mental health are from the youth at $64 \%$ of the youth surveyed, with almost half reporting symptoms matching those of severe anxiety [11]. This result is expected as students are left devastated with interrupted educational plans and work placements [12], especially international students that may have made many sacrifices to study abroad. Social work research would serve a crucial role in helping students stand up, find the will to cope with distress, and show resilience to the various challenges faced.

Universities and colleges already have student wellness centres [4] and mental health resources to support their students. Yet, these can be often generalized to all students and left unused by many when in need of help. Initiatives and social programs that cater specifically to the needs of the international community and assess the magnitude of crises would lead to much more proactive and effective interventions for international students [10]. Social work should emphasize two aspects that focus on the two fundamental challenges outlined in this paper financial hardships and social support.

For instance, financial distress may be alleviated by orienting international students to community resources to ensure their access to nutrition and shelter. Additional interventions could include strategic assistance in the job-searching process, housing, or directing students to financial relief or bursary programs with greater eligibility for the international community, even for those studying from their home countries. Social work initiatives can also raise awareness and advocate for international students to other well-known public programs and 
charities [4] in acquiring special funds. The government can, of course, play the most significant role by extending current relief programs such as the Canadian Emergency Student Benefit (CESB) or by implementing other similar programs [12] to acknowledge the advocacy efforts of financial shortcomings.

Secondly, social services offered by educational institutions and social initiatives should continue and further specialize in specific resources through talk lines, virtual meetings, and inperson chats or support communities. Students should be encouraged to slowly share their sentiments and experiences with faculty counsellors without being judged or preached. Educational workshops [10] for staff and students would also help raise awareness of this issue to mitigate the impacts of xenophobia and cultural differences. These efforts would motivate international students to become proactive to expand their social circles and ultimately lessen the state of vulnerability amidst the pandemic.

\section{Conclusion}

International students are a notable boost to the Canadian economy and represent the diversity of Canada with unique cultural differences. However, they are excluded from social and economic response measures and are a much more socially- and financially vulnerable group. With economic downturns on the global scale, current and prospective students, and their families, already face challenges due to their immigration status, especially those from developing nations [4]. Canada is a relatively expensive place to live in but is also a recognized acceptor of diversity, which is why students have immigrated with hopes for a brighter future. Therefore, addressing the concerns and struggles of international students during the pandemic with the proposed interventions in this paper is a significant step to promoting social justice for all groups. The actions of governments, educational institutions, and the general society towards international students during the pandemic could heavily influence how prospective international students view the countries for post-secondary education in the future.

\section{References}

[1] Dennis MJ. COVID-19 will accelerate the decline in international student enrollment. Enroll Manag Rep. 2020;24(4):1-5.

[2] Statistics Canada. International Student Enrolment in Postsecondary Education Programs Prior to COVID-19. Available from: https://www150.statcan.gc.ca/n1/pub/11-626-x/11-626-x2020003-eng.htm [accessed 26 July 2021]

[3] Pei S, Friedel J. The rising cost of being foreign: Impact of differential tuition on international students. JCIHE. 2019;9(Winter):56-7.

[4] Firang D. The impact of COVID-19 pandemic on international students in Canada. Int Soc Work. 2020;63(6):820-4.

[5] Hutcheson S. Sexual violence, representation, and racialized identities: Implications for international students. Educ \& LJ. 2020;29(2):191-221.

[6] Government of Canada. Funding: Canada Summer Jobs - Screening for eligibility. Available from: https://www.canada.ca/en/employment-social-development/services/funding/canada-summer-jobs/screeningeligibility.html [accessed 26 July 2021].

[7] Scott C, Safdar S, Desai Trilokekar R, El Masri A. International Students as 'Ideal Immigrants' in Canada: A disconnect between policy makers' assumptions and the lived experiences of international students. Comp Int Edu. $2015 ; 43(3)$.

[8] Statistics Canada. Perceptions of personal safety among population groups designated as visible minorities in Canada during the COVID-19 pandemic. Available from: https://www150.statcan.gc.ca/n1/pub/45-280001/2020001/article/00046-eng.htm [accessed 26 July 2021]. 
[9] Sahu P. Closure of universities due to coronavirus disease 2019 (COVID-19): Impact on education and mental health of students and academic staff. Cureus. 2020;12(4).

[10] Chirkov V, Safdar S, de Guzman J, Playford K. Further examining the role motivation to study abroad plays in the adaptation of international students in Canada. Int J Intercult Relat. 2008;32(5):427-40.

[11] Statistics Canada. The Daily - Canadians' mental health during the COVID-19 pandemic. Available from: https://www150.statcan.gc.ca/n1/daily-quotidien/200527/dq200527b-eng.htm [accessed 26 July 2021].

[12] Gosselin JS, Godbout L, Gagné-Dubé T, St-Cerny S. Finances of the Nation: The economic response of governments in Canada to COVID-19 in the first three months of the crisis. Can Tax J. 2020;68(3):863-90.

Declarations of Interest: None

Data sharing is not applicable to this paper because no new data was created or analyzed.

\section{Acknowledgements}

Not applicable.

\section{Disclosure Statement}

No potential conflict of interest was reported by the authors.

\section{Funding Acknowledgements}

Not applicable. 